\title{
Matriz metodológica para análise de comunidades virtuais de prática
}

\author{
Antonieta Rocha e Alda Pereira
}

\section{Resumo}

Neste artigo propomo-nos descrever a metodologia usada na análise de comunidades virtuais na rede. Dada a existência de Grupos, Redes, Coletivos e Comunidades que povoam a Rede global, importa refletir acerca do quadro metodológico a aplicar sempre que se persiga a intenção de investigar em particular uma destas entidades. Com o objetivo de analisar e caraterizar sete comunidades online, procurando evidenciar os traços que tipificam eventuais comunidades virtuais de prática, foi realizado um estudo de casos múltiplos, de natureza predominantemente qualitativa. Metodologicamente privilegiou-se a observação continuada da realidade vivida nessas comunidades, a realização de entrevistas online semiestruturadas aos moderadores, a análise de redes sociais, procurando analisar as dinâmicas interrelacionais, tendo-se complementado o estudo com o recurso à aplicação de questionários online aos respetivos participantes. Este artigo, para além de procurar dar conta da metodologia usada, apresenta uma matriz de análise dos dados que permite identificar, em face de estruturas localizadas na rede, a existência de comunidades virtuais de prática e a abrangência dos traços que as tipificam.

Palavras-chave:

metodologia; matriz de análise; estudos de caso; investigação online; comunidades virtuais de prática. 


\section{Methodological matrix for the analysis of virtual communities of practice}

Abstract. In this article, we propose to describe the methodology used in the analysis of virtual communities on the Internet. Given the existence of the Groups, Networks, Collectives and Communities that populate the Web, it is important to reflect on the methodological framework to be applied when pursuing the investigation of one of these particular entities. With the objective of analyzing and characterizing seven online communities and in seeking to show the traits that typify possible virtual communities of practice, a predominantly qualitative study of multiple cases was conducted. The methodology favored the continued observation of the lived reality in these communities, the conducting of moderated semi-structured online interviews, the analysis of social networks and the attempt to analyze inter-personal dynamics; while the study was supplemented by the application of online questionnaires to the respective participants. This article does not only intend to determine the methodology used, but it also presents a data analysis matrix which allows to identify, in the face of structures located in the network, the existence of virtual communities of practice and the reach of the features that typify them.

Keywords: methodology; evaluation matrix; case studies; online investigation; virtual communities of practice.

\section{Matrice méthodologique pour l'analyse des communautés virtuelles de pratique}

Résumé. Dans cet article, nous nous proposons de décrire la méthodologie utilisée pour l'analyse des communautés virtuelles sur le réseau. Compte tenu de la présence de groupes, de réseaux, de collectifs et de communautés qui peuplent le Réseau global, il convient de réfléchir sur le cadre méthodologique à appliquer dès lors que l'on envisage d'étudier l'une de ces entités en particulier. Dans le but d'analyser et de caractériser sept communautés en ligne, en cherchant à mettre en évidence les traits qui caractérisent d'éventuelles communautés virtuelles de pratique, une étude de cas multiples, essentiellement de nature qualitative, a été réalisée. Sur le plan méthodologique, nous avons privilégié l'observation continue de la réalité vécue dans ces communautés, la réalisation d'entretiens en ligne semistructurés aux modérateurs, l'analyse de réseaux sociaux, en cherchant à analyser les dynamiques interrelationnelles, l'étude ayant été complétée par l'application de questionnaires en ligne aux participants respectifs. En plus de rendre compte de la méthodologie utilisée, cet article propose une matrice d'analyse des données qui permet d'identifier, au vu des structures repérées sur internet, l'existence de communautés de pratique virtuelles et l'étendue des traits qui les caractérisent.

Mots-clés: méthodologie; matrice d'analyse; études de cas; recherche en ligne; communautés virtuelles de pratique.

\section{Matriz metodológica para análisis de comunidades virtuales de práctica}

Resumen. En este artículo, proponemos una descripción de la metodología empleada para el análisis de comunidades virtuales en Internet. Dada la existencia de los grupos, redes, colectivos y comunidades que inundan la red global, es importante reflexionar sobre el marco metodológico a aplicar cuando se pretenda investigar en particular una de estas entidades. Con el objetivo de analizar y describir las siete comunidades online y velando por la identificación de los posibles rasgos característicos de las comunidades virtuales de práctica, se realizó un estudio de múltiples casos, mayoritariamente cualitativos. A nivel metodológico, se observó de forma continuada la realidad vivida en esas comunidades, se realizaron entrevistas online semiestructuradas a los moderadores y se analizaron las redes sociales, todo ello buscando analizar las dinámicas interrelacionales. El estudio se completó con la aplicación de cuestionarios online a los respectivos participantes.

Este artículo, además de intentar narrar la metodología que se ha utilizado, presenta una matriz de análisis de datos que permite identificar, examinando las estructuras encontradas en la red, la existencia de comunidades virtuales de práctica y el alcance de los rasgos que la caracterizan.

Palabras clave: metodología; matriz de análisis; estudios de caso; investigación online; comunidades virtuales de práctica. 


\section{Introdução}

Irrompem em ambientes virtuais novas "Formas de Organização" (Wenger \& Trayner, 2011), "Granularidades" / "More" (Anderson \& Dron, 2007) e "Grupos e Redes" (Downes, 2007).

Assumindo que o conhecimento está "distributed across a network of people" (Downes, 2006, p.10) e "The capacity to form connections between sources of information, and thereby create useful information patterns, is required to learn in our knowledge economy" (Siemens, 2004, An Alternative Theory, para. 5) estas estruturas, em oposição ao indivíduo, irão permitir benefícios para cada elemento a elas pertencente.

Contudo, estudar estas formas organizativas, (des)localizadas na rede, um campo ainda em aberto, desafia, inevitavelmente, opções metodológicas tradicionais.

O interesse por esta temática surgiu de um trabalho alargado desenvolvido pelas autoras e que se propôs analisar e caracterizar sete comunidades virtuais de prática (CoP) de quatro contextos (educacional, profissional, empresarial e social). A riqueza das interações bem como as especificidades do ambiente virtual em que as mesmas estão ancoradas fez emergir uma nova matriz metodológica para a sua análise - numa primeira fase, de forma isolada - mas que permitiu, num segundo momento, a comparação entre os contextos investigados.

Partindo de um breve enfoque teórico, apresenta-se a seguir, em traços gerais, a metodologia usada e a matriz construída para analisar de forma abrangente todos os dados recolhidos.

\section{Em torno das redes}

De acordo com Downes (2006), uma Rede pode ser caracterizada através de 3 elementos principais: (a) entidades - as coisas que estão conectadas e que enviam e recebem sinais; (b) conexões - o link ou canal entre as entidades e que pode ser representado física ou virtualmente; (c) sinais - a mensagem enviada entre as entidades e que deve ser interpretada pelo recetor. Também as Redes (Downes, 2006) podem variar, de acordo com um conjunto de propriedades, a saber: (a) a densidade - número de entidades a que cada uma está ligada; (b) velocidade - rapidez com que uma mensagem se move para uma entidade; (c) fluxo - quantidade de informação processada por cada entidade, incluindo as mensagens enviadas e recebidas, para além da transferência de mensagens para outras entidades; (d) plasticidade - frequência de conexões criadas e abandonadas; (e) grau de ligação - em função da densidade, velocidade, fluxo e plasticidade. Considera, ainda, que a Rede: (a) permite Pontes para outras formas (CoP); (b) tem Autonomia (encontrando-se entre o Indivíduo e o Grupo), propiciando a interação entre o Conhecimento e Partilha conduzindo ao 
Conhecimento; (c) é Conetiva - ligando o Indivíduo à Aprendizagem e Informação disponíveis e (d) apresenta Diversidade (diferentes identidades) entre o Membro e a Rede.

No que concerne ao aspeto da aprendizagem e da expectativa dos membros quanto ao que buscam e irão encontrar na Rede, afirma Downes (2007) que cada indivíduo seleciona e gere a aprendizagem da melhor forma. Assim, os membros têm expectativas em usar a Rede para obter informações e pontos de vista, contactos e sugestões, fora das conexões dos seus grupos mais familiares e a que pertencem (Anderson e Dron, 2007).

Também, agindo enquanto nó responsável, (com)partilham conhecimentos e obtêm, na Rede, a resolução rápida de problemas e acesso a recursos (Wenger, Trayner e de Laat, 2011). A propósito da aprendizagem, embora não estando explícita uma dimensão coletiva (aspeto diretamente relacionado com o comprometimento entre os membros) a mesma ocorre pela forma como os membros e interessados criam, negoceiam e mudam a narrativa do valor criado (Wenger \& Trayner, 2011). Daí decorre que esta aprendizagem se consubstancia num valor enquanto ajuda aos outros, acesso a múltiplas perspetivas e/ou diálogos entre os membros bem como a resposta a consultas e eventuais dúvidas surgidas o que, consequentemente, propicia laços de aprendizagem entre as conexões estabelecidas (Wenger, Trayner e de Laat, 2011).

As Redes permitem o aparecimento de comunidades de prática (Downes, 2007), já que uma comunidade pode ser definida enquanto um conjunto de indivíduos que trocam mensagens sem qualquer impedimento e onde, como tal, esse movimento de troca de mensagens (trazer e levar) é realizado sem barreiras. Sendo certo que os direitos de autor, as marcas, a propriedade do software surgem enquanto barreiras para a comunicação e troca de pensamentos e ideias, a Rede permite a sua utilização sem qualquer restrição. Esta utilização livre deve-se à colocação de todas as informações na grande rede que é a internet e, a partir daí, cada utilizador poderá utilizá-la da meIhor forma que entender.

\section{Comunidades de prática}

Partindo do conceito de aprendizagem situada (Lave e Wenger, 1991), essa aprendizagem "involved a process of engagement in a community of practice" (Smith 2003, 2009, para. 1) assente na premissa de que a aprendizagem é social e que surge a partir da nossa experiência quotidiana.

Qualquer que seja o tipo, uma comunidade de prática assenta numa estrutura básica que "is a unique combination of three fundamental elements: a domain of knowledge, which defines a set of issues; a community of people who care about this domain; and the shared practice that they are developing to be effective in their domain" (Wenger, McDermott and Snyder, 2002, p. 27). 
Wenger (1998) argumenta que quando estamos numa comunidade de prática à qual pertencemos estamos em território familiar, isto é, experimentamos competência e somos reconhecidos como competentes, sabemos como interagir com os outros membros, compreendemos por que eles fazem determinadas coisas porque compreendemos o empreendimento do qual os participantes estão responsáveis, compartilhamos os recursos comunicacionais utilizados e conhecemos as suas atividades. Se entramos em contacto com novas práticas, aventuramo-nos em território não familiar: não sabemos absolutamente nada como interagir com os outros, não compreendemos as subtilezas do empreendimento, e faltam-nos as referências partilhadas e que são usadas pelos participantes.

\section{Opções metodológicas}

Propondo-nos investigar sete comunidades virtuais de prática em quatro contextos, importava a opção por uma metodologia de análise que revelasse as especificidades, tanto das próprias comunidades, como do ambiente virtual em que as mesmas se encontravam ancoradas. Neste contexto, optámos por uma investigação de cariz qualitativo, campo de investigação por direito próprio (Denzin e Lincoln, 1994) e que se focaliza, entre outros aspetos, na tentativa de perceber as situações na sua singularidade (Patton, 1985).

Pretendendo estudar as especificidades das comunidades no seu ambiente natural, pareceu-nos a natureza qualitativa a mais adequada, pois "os métodos qualitativos não podem ser encarados como independentes do processo de investigação e da questão a estudar" (Flick, 2005, p.1). Com efeito, procurar conhecer a forma como os atores se relacionam em ambiente virtual, como percecionam o mesmo, que expetativas Ihe acordam e como se comprometem com a sua história, exigia, do nosso ponto de vista, a opção por um estudo realizado, tanto quanto possível, no ambiente em que se movimentavam os atores.

Quer seja "simples ou complexo" (Stake, 1994, p. 236), assumindo que o estudo de caso (a) trabalha com situações tecnicamente distintas, nas quais poderão existir mais variáveis de interesse do que itens de informação, e com um só resultado final; (b) depende de múltiplas fontes de evidência, necessitando que a informação convirja de forma triangulada; (c) beneficia de proposições teóricas anteriores que guiem a recolha e análise dos dados (Yin, 2009), seria no nosso estudo a opção metodológica a adotar.

Tendo em conta que as comunidades a estudar se radicavam em diferentes contextos, optámos por estudos de caso múltiplos, já que podem ser utilizados (Stake, 2007) a fim de promover uma "coordenação importante entre os estudos individuais", o que irá permitir "um estudo alargado a vários casos, similares ou não, escolhidos porque a sua compreensão irá levar a um melhor entendimento, até a uma melhor 
teorização, acerca de uma ainda maior coleção de casos" (Stake, 1994, p. 237). Yin (1986) refere-se ao estudo de casos múltiplos sempre que o mesmo estudo necessite e contenha mais de um caso único, encarado como se tratasse de experiências múltiplas, devendo seguir-se uma lógica de replicação, prevendo os mesmos resultados para todos os casos

Tipo 1 - um caso único com uma unidade de análise; (b) Tipo 2 - um caso único com múltiplas unidades de análise "embedded"; (c) Tipo 3 - estudos de caso múltiplos com apenas uma unidade de análise; (d) Tipo 4 - estudos de casos múltiplos com múltiplas unidades de análise.

O design da nossa investigação veio a consubstanciar-se em quatro contextos, sendo dois deles com apenas uma unidade de análise em cada - educacional e empresarial -, um com três subunidades - contexto social - e um com duas subunidades - contexto profissional.

Dado o ambiente virtual em que as comunidades em estudo se ancoravam, importa ainda referir os procedimentos éticos: (a) A análise a cada uma das sete comunidades iniciou-se após consentimento escrito de cada administrador, decorrente de e-mail informando da finalidade e objetivos do estudo; (b) optámos por uma observação não participante que permitisse analisar as comunidades sem que a nossa presença fosse notada, não chamando a atenção para nós, observando o que era comum durante o tempo suficiente para compreender "o que, para este caso, significa ser comum." (Stake, 2007, p. 59); (c) Para as entrevistas semiestruturadas aos administradores procedemos a contactos prévios, informando os objetivos e solicitando disponibilidade para a entrevista e gravação áudio; (d) Para as entrevistas aos membros da comunidade educacional começámos por solicitar autorização ao administrador, enviando o guião da entrevista e foi o próprio que dinamizou os membros voluntários com que contactámos posteriormente, confirmando autorização para gravação áudio e posterior envio da transcrição, o que cumprimos; (e) O questionário foi previamente apresentado aos administradores em anexo ao pedido de autorização e excetuando um administrador que retirou questões, foi autorizado na versão original; (f) procedemos à codificação de comunidades e membros, a fim de manter o sigilo das comunidades estudadas, o anonimato e confidencialidade das declarações de todos os participantes.

\section{Recolha e tratamento de dados}

Tendo em conta os objetivos do estudo, procurámos uma descrição pormenorizada e rigorosa, de forma a assegurar a fiabilidade do mesmo e privilegiar a triangulação de dados uma vez que tínhamos um estudo de casos múltiplos.

Como metodologia analisámos inicialmente os resultados de cada comunidade em separado; depois, visando a comparação e triangulação dos dados - e sempre que 
possível -, procedemos à análise comparada entre os resultados das diferentes comunidades.

Como técnicas de recolha de dados privilegiámos a observação, o inquérito por entrevista e por questionário, complementados pela técnica de análise de redes sociais.

\subsection{Observação}

Elegemos a observação, enquanto imersão no campo, para iniciar a investigação em cada comunidade, permitindo o seu conhecimento e fazendo emergir outras questões a serem aprofundadas por outras técnicas, nomeadamente a do inquérito. Perante um foco de observação vasto e rico afigurou-se indispensável, a construção de um guião de observação (Stake, 2007) de interações por comunidade, com as seguintes dimensões: data e hora, interações, estilo de linguagem, intenção da mensagem, tipo de participação, relações de tensão, função afetiva, saudação e despedida. Interessava-nos recolher dados acerca dos temas mais discutidos, membros que se evidenciavam, níveis de participação, nível da (não) participação da administração/moderação, (não) cumplicidade entre os membros e os conflitos ocorridos e sua gestão. Mostrando-se eficaz, foi replicado para todas as comunidades e propiciou um conhecimento gradual da dinâmica da comunidade. Este guião foi objeto de interpretação direta.

Para as comunidades que dispunham de um centro de estatísticas atualizado, criámos outro guião de observação -"cronograma"-, para registo dos valores mensais de novas mensagens, novos tópicos e novos membros, dados recolhidos a partir do centro de estatística de cada comunidade ou contabilizados manualmente por nós e que foram trabalhados em estatística descritiva e gráficos representativos dos aludidos valores.

Elaborámos ainda, a partir do primeiro mês de observação, um diário do investigador para cada comunidade observada onde, sem grande estrutura pré-definida, fomos registando de forma cronológica as nossas observações bem como as asserções e inferências que, de forma transversal e abordando todos os aspetos (desde a dinâmica, níveis de acesso, estatísticas, problemas tecnológicos, ...) acompanharam toda a investigação. A sua (re)leitura frequente permitiu-nos fazer emergir novas questões que justificaram o recurso a outras técnicas. Este diário do investigador configurou-se como o nosso guião principal, tendo sido criado um para cada comunidade estudada. Sem qualquer preocupação de sistematização, acolheu a forma final de um diário e foi tratado por interpretação direta.

\subsection{A Entrevista}

Decorrente dos dados da observação, decidimos realizar entrevistas a administradores, visando esclarecer: (a) objetivos e razões que os levaram a promover, criar e dinamizar as comunidades estudadas e (b) diferentes aspetos inerentes até à forma 
como se (não) alimentavam as suas comunidades, a fim de poder, também, confirmar algumas evidências e informações resultantes da nossa observação e da análise das informações e "editais" publicados no portal de cada comunidade.

Surgiu também como importante tentar perceber da parte dos membros de uma das comunidades, que no decurso da observação se verificou ser muito dinâmica, as suas impressões sobre a referida comunidade, a razão que os levaram a integrá-la, as razões porque nela permaneciam, qual a opinião face à mesma e qual a mais-valia que dela estavam a usufruir. Estes objetivos justificaram a realização de entrevistas a vários membros dessa comunidade. Considerados estes pressupostos, decidimos adotar a entrevista semiestruturada. Elaborámos, assim, para cada uma das entrevistas, um conjunto de questões em consonância com os objetivos específicos definidos. Assegurados os princípios éticos e deontológicos, a maioria das entrevistas consumou-se com recurso a ferramentas informáticas - Skype e Messenger. Afigurou-se-nos assim (Holsti, 1969) a análise de conteúdo como a forma mais adequada ao tratamento dos testemunhos e informações recolhidas.

Iniciámos por uma "leitura flutuante" (Bardin, 2004), a fim de estabelecer um primeiro contacto com os documentos, a que se seguiram posteriores leituras - dada a riqueza e extensão do corpus analisado. Após esta fase, começaram a emergir as grandes categorias e subcategorias, conforme os objetivos pré-estabelecidos, o quadro teórico e o resultado da nossa observação. Tendo sido possível a sua replicação pelas onze entrevistas, encontrámos cinco categorias: motivação; estruturação; dimensão social; coesão e níveis de satisfação.

Ainda que tenhamos procedido ao registo de forma tradicional, de facto o software Nvivo permitiu-nos a codificação, de uma forma mais dinâmica, de todos os protocolos de entrevista. Numa fase posterior, permitiu-nos ainda trabalhar a codificação cruzada e transversal entre administradores e entre administrador e membros.

\subsection{O Questionário}

Os estudos de caso múltiplos de investigação qualitativa podem incluir instrumentos que procuram evidências quantitativas (Yin, 2009). Visando a triangulação de dados, complementar a observação e confirmar as nossas inferências face a uma amostra de membros entrevistados de uma das comunidades, decidimos aplicar um questionário.

Assumindo que pretendíamos conseguir perceções acerca do (não) funcionamento de cada comunidade, o caráter de anonimato do questionário afigurava-se como facilitador. Também e porque estávamos a investigar comunidades em ambiente virtual, não faria sentido ponderar outra forma de aplicação que não a online.

Conscientes dos potenciais riscos - interação indireta e não respostas, entre outros (Neuman, 2006; Ghiglione e Matalon, 2005), o questionário desenhado tinha como objetivos: (a) esclarecer aspetos de adesão a mais fóruns online; (b) inventariar razões 
de adesão a esta comunidade e antiguidade na mesma; (c) analisar/esclarecer a frequência de acesso aos diferentes espaços da comunidade; (d) analisar a representação quanto à participação na comunidade; (e) inventariar o tipo e benefícios da participação na comunidade; (f) avaliar a comunidade no momento presente; (g) identificar e inventariar as expectativas face à comunidade.

Para construção do mesmo, optámos pelo Google Docs em função dos aspetos da clareza, facilidade e acesso fácil. Assegurados os procedimentos éticos da validação, a aplicação dos questionários decorreu a partir da disponibilização do link num tópico do fórum da própria comunidade com prévia autorização do administrador.

No que concerne ao seu tratamento, e superando o tratamento incipiente da própria ferramenta informática, decidimos proceder a uma análise em função dos objetivos da nossa investigação, optando pela estatística descritiva. Numa primeira fase, e no que concerne às perguntas de resposta fechada, os resultados foram sistematizados em quadros de frequências absolutas e relativas.

Relativamente às perguntas de resposta aberta, recorremos à análise de conteúdo da qual, e de forma indutiva, emergiram as categorias dimensão social e níveis de satisfação, que incluímos na análise de cada comunidade.

\subsection{Análise de Redes Sociais}

A triangulação dos resultados da observação com os dados das entrevistas, questionários e diário do investigador, fizeram emergir a necessidade de tentar perceber, mais em profundidade, o nível da interação entre os membros. Optámos, na senda de outros autores (Murillo, 2002), por realizar uma análise das interações explícitas entre os atores, usando um fórum da comunidade educacional e dois outros - um de cariz mais profissional, ligado à atividade da comunidade e outro de caráter mais generalista, para ver se o nível de interação (não) era discrepante - de cada uma das comunidades profissionais e de uma comunidade social.

Tínhamos como objetivo procurar perceber as "relações entre os actores individuais ou colectivos" (Lemieux e Ouimet, 2008, p. 7), recorrendo ao software Ucinet 6 para o Windows Versão 6.289 (Borgatti, Everett e Freeman, 2002). Este software, que pode ser definido como "um conjunto de métodos para a análise da estrutura de relações sociais dentro de um grupo" (Bratkovic, Antonic, Ruzzier, 2009, p. 3), tem como função a criação e manipulação de matrizes que representam matematicamente as redes, onde os seus elementos são as relações. Elaborámos as matrizes correspondentes a cada rede com o objetivo de calcular os rácios adiante mencionados. Também, e sempre que considerámos ser relevante e mais explícita uma representação gráfica, procedemos à exportação das referidas matrizes para o software NetDraw 2.097.

Para a análise dessas redes, dado o nosso interesse em analisar mais profunda e pormenorizadamente a interação e dinâmica destes membros nos fóruns em estudo, 
centrámos a nossa atenção no tamanho, na Densidade e no Grau de Centralidade da Rede (Rocha, 2013), analisando percentualmente os rácios grau normalizado de saída e entrada.

\section{A matriz de análise}

Considerando que os estudos de caso múltiplos envolvem a recolha e análise dos dados de vários casos, existem (Merriam, 1998) duas etapas de análise - a análise dentro do caso e a análise cruzada de casos. Enquanto para a primeira, o caso é tratado enquanto caso abrangente per se, numa segunda etapa - a análise cruzada - será necessário buscar abstrações entre os casos e encontrar explicitações globais.

Por conseguinte, tendo em conta as características próprias e a história particular de cada comunidade e, ainda, a riqueza aliada às diferentes fontes de dados, tornouse imperativo a criação de uma matriz de análise homogénea que visasse três objetivos: (a) demonstrar as particularidades de cada comunidade em estudo; (b) permitisse uma triangulação e comparação entre as várias comunidades de cada contexto; (c) possibilitasse a comparação entre contextos.

A matriz então criada demonstrou-se facilitadora destes objetivos e permitiu-nos incluir os dados recolhidos quer através da nossa observação, bem como do questionário online aplicado aos membros de 6 comunidades e entrevistas a cinco administradores e 6 membros da comunidade educacional. Conforme se assinala a seguir, é objetivada em torno de 5 grandes dimensões - Caracterização da Comunidade (A), Estrutura da Comunidade (B), Dinâmica da Comunidade (C), Relevância da Comunidade (E) e Análise Global da Comunidade (D).

Apresenta-se o quadro correspondente a cada dimensão, com a explicitação das subdimensões, e respetivos indicadores. 
Quadro 1. Caraterização da comunidade (A)

\begin{tabular}{|l|l|}
\hline \multicolumn{1}{|c|}{ SUBDIMENSÃO } & \multicolumn{1}{c|}{ INDICADORES } \\
\hline Finalidade/ Missão da \\
Comunidade & $\begin{array}{l}\text { Missão da comunidade (através da observação e análise } \\
\text { dos editais da homepage; qual o domínio;) } \\
\text { Apoios financeiros; Fim (não) lucrativo; Forma de } \\
\text { subsistência e manutenção da comunidade }\end{array}$ \\
\hline Natureza da Comunidade & $\begin{array}{l}\text { Caracterização da comunidade (profissional, social, } \\
\text { empresarial ou educacional), a partir dos dados do } \\
\text { questionário, nomeadamente, o nível etário, profissão e } \\
\text { habilitações literárias; Identificação do perfil etário e nível } \\
\text { de atividade dos membros (perceber se maioritariamente } \\
\text { estão em idade ativa, são jovens, ...) }\end{array}$ \\
\hline Espaços de Comunicação & $\begin{array}{l}\text { Verificação da possibilidade de ser facilmente } \\
\text { encontrada a partir de qualquer motor de busca; Forma } \\
\text { de entrada - por convite ou apenas registo. Tipo de } \\
\text { registo; Existência (ou não) de algum controlo à entrada } \\
\text { de um novo membro e quem exerce esse controlo }\end{array}$ \\
\hline Criação e Evolução & $\begin{array}{l}\text { Origem e história da própria comunidade; Razão para a } \\
\text { sua criação; } \\
\text { Marco temporal para início e posteriores mudanças } \\
\text { Modo de divulgação inicial; Experiência anterior do } \\
\text { administrador e membros; evolução da equipa de } \\
\text { administração e moderação }\end{array}$ \\
\hline
\end{tabular}

Quadro 2. Estrutura da comunidade (B)

\begin{tabular}{|l|l|}
\hline \multicolumn{1}{|c|}{ SUBDIMENSÕES } & \multicolumn{1}{c|}{ INDICADORES } \\
\hline Espaço(s) & $\begin{array}{l}\text { Estruturação dos diferentes espaços (a partir do seu } \\
\text { administrador e/ou testemunhos publicados nos editais) }\end{array}$ \\
\hline Hierarquia & $\begin{array}{l}\text { Tipo de hierarquização existente, tanto nos espaços, } \\
\text { como quanto a eventuais equipas; } \\
\text { Existência (ou não) de hierarquia vertical, horizontal } \\
\text { ou funcional, quer através dos testemunhos do } \\
\text { administrador, quer a partir da nossa representação } \\
\text { gráfica }\end{array}$ \\
\hline Moderação e gestão dos membros & $\begin{array}{l}\text { Funções, seleção e constituição da equipa de } \\
\text { moderação; } \\
\text { Como e por quem é regulada a gestão dos membros }\end{array}$ \\
\hline Conteúdos & Caracterização e regulação dos conteúdos publicados \\
\hline Iniciativas & $\begin{array}{l}\text { Explicitação e caracterização das diferentes iniciativas } \\
\text { da comunidade }\end{array}$ \\
\hline
\end{tabular}


Quadro 3. Dinâmica da Comunidade (C)

\begin{tabular}{|l|l|}
\hline \multicolumn{1}{|c|}{ SUBDIMENSÕES } & \multicolumn{1}{|c|}{ INDICADORES } \\
\hline Fluxo de Membros & $\begin{array}{l}\text { Número de membros (inicial e atual); reconstituir o } \\
\text { percurso evolutivo recorrendo ao centro de estatística, } \\
\text { editais da própria comunidade e testemunho do } \\
\text { administrador; percurso evolutivo da entrada de novos } \\
\text { membros. Adesão e/ou (não) exclusividade por parte de } \\
\text { cada membro a esta comunidade, a partir dos dados } \\
\text { do questionário, tentando perceber: a) se cada membro } \\
\text { (não) pertence a outros fóruns online; b) em caso } \\
\text { afirmativo, qual o número dos restantes fóruns; c) forma } \\
\text { de conhecimento deste fórum, d) antiguidade no fórum }\end{array}$ \\
\hline Participação & $\begin{array}{l}\text { Participação a partir: a) frequência de acesso; b) níveis } \\
\text { e tipo de participação; c) (não) desfasamento entre } \\
\text { leitura e participação ativa; d) frequência e relação entre } \\
\text { membros, mensagens e tópicos; e) comportamento face } \\
\text { a cada diferente espaço da comunidade }\end{array}$ \\
\hline Valorização da Dinâmica & $\begin{array}{l}\text { Valor da participação para estes membros; pertinência } \\
\text { de soluções a problemas e sugestões de outros } \\
\text { membros }\end{array}$ \\
\hline Análise de Interações & $\begin{array}{l}\text { Análise de redes sociais, com base em 2 fóruns de cada } \\
\text { comunidade - um mais técnico e um mais generalista }\end{array}$ \\
\hline Conflitos e Gestão de Conflitos & $\begin{array}{l}\text { Coesão da equipa decisora - administrador e } \\
\text { moderadores; Conhecimento com outros membros após } \\
\text { a adesão à comunidade; Conhecimento prévio - a nível } \\
\text { pessoal e/ou profissional - com outro(s) membro(s); Tipo } \\
\text { de contactos mantidos com os outros membros; } \\
\text { Manutenção de futuros contactos em caso hipotético de } \\
\text { extinção da comunidade. Tipo de cumplicidades entre } \\
\text { membros e a existência da confiança mútua na resposta } \\
\text { dada }\end{array}$ \\
\hline Coesão & $\begin{array}{l}\text { Existência de conflitos e forma de resolução } \\
\text { (testemunhos do administrador e/ou membros). } \\
\text { Necessidade de intervenção da equipa decisora ou } \\
\text { resolução natural do conflito (ex. voluntário afastamento } \\
\text { do(s) membro(s) intervenientes) }\end{array}$ \\
\hline $\begin{array}{l}\text { Ambiente vivenciado na comunidade, a partir dos } \\
\text { testemunhos de administradores e membros }\end{array}$ \\
\hline
\end{tabular}


Quadro 4. Relevância da comunidade (D)

\begin{tabular}{|l|l|}
\hline \multicolumn{1}{|c|}{ SUBDIMENSÕES } & \multicolumn{1}{c|}{ INDICADORES } \\
\hline Expectativas Iniciais & $\begin{array}{l}\text { Grau de concordância entre as expetativas iniciais } \\
\text { do administrador e a comunidade atual; grau de } \\
\text { concretização dos objetivos do administrador. }\end{array}$ \\
\hline Valor da Comunidade & $\begin{array}{l}\text { Mais-valia que a pertença na comunidade, } \\
\text { consubstanciada na participação, representa para cada } \\
\text { membro; Importância da aprendizagem informal existente } \\
\text { na comunidade }\end{array}$ \\
\hline Interesse na Comunidade & Utilização privilegiada da comunidade e respetivas razões \\
\hline Partilha & $\begin{array}{l}\text { Relevância, para cada membro, da partilha e opinião } \\
\text { acerca do repositório existente }\end{array}$ \\
\hline
\end{tabular}

Quadro 5. Análise Global da Comunidade (E)

\begin{tabular}{|l|l|}
\hline SUBDIMENSÕES & \multicolumn{1}{|c|}{ INDICADORES } \\
\hline Inovação e Criatividade & $\begin{array}{l}\text { Relato de projetos inovadores e que demonstrem } \\
\text { criatividade }\end{array}$ \\
\hline Tecnologia & $\begin{array}{l}\text { Aspetos ligados com a tecnologia, nomeadamente } \\
\text { com a literacia tecnológica dos membros e forma de } \\
\text { minimização dos constrangimentos inerentes à eventual } \\
\text { iliteracia }\end{array}$ \\
\hline Importância da Virtualidade & $\begin{array}{l}\text { Importância do ambiente virtual para a continuidade e } \\
\text { sucesso da mesma }\end{array}$ \\
\hline $\begin{array}{l}\text { Aspetos que Limitam o } \\
\text { Desenvolvimento da Comunidade }\end{array}$ & $\begin{array}{l}\text { Aspetos relevantes negativos que possam limitar o } \\
\text { desenvolvimento da comunidade }\end{array}$ \\
\hline $\begin{array}{l}\text { Aspetos que Facilitam o } \\
\text { Desenvolvimento da Comunidade }\end{array}$ & $\begin{array}{l}\text { Aspetos relevantes positivos que poderão contribuir para } \\
\text { a continuidade e desenvolvimento da comunidade }\end{array}$ \\
\hline Perspetivas de Desenvolvimento & Análise dos projetos futuros da comunidade \\
\hline $\begin{array}{l}\text { Fatores Extrínsecos ou } \\
\text { Intrínsecos que Apontam para o } \\
\text { Futuro }\end{array}$ & $\begin{array}{l}\text { Indícios de possíveis constrangimentos, externos ou } \\
\text { internos à comunidade, que poderão apontar para a sua } \\
\text { continuidade ou pô-la em risco }\end{array}$ \\
\hline $\begin{array}{l}\text { Tipo de Impacto da Comunidade } \\
\text { nos Membros }\end{array}$ & $\begin{array}{l}\text { Análise dos fatores de reconhecimento recebidos a nível } \\
\text { interno e externo }\end{array}$ \\
\hline Níveis de Satisfação & Avaliação do funcionamento da própria comunidade \\
\hline $\begin{array}{l}\text { Caracterização Aplicada à Teoria } \\
\text { das CoP (Wenger) }\end{array}$ & $\begin{array}{l}\text { Caracterização à luz da teoria das comunidades virtuais } \\
\text { de prática de Etienne Wenger, nomeadamente definição } \\
\text { do domínio; estádio de desenvolvimento; trajetórias dos } \\
\text { membros e graus de participação }\end{array}$ \\
\hline
\end{tabular}

Fonte: Elaboração própria 
A caraterização da comunidade permite traçar um quadro geral sobre a sua finalidade e natureza, a sua abertura através dos espaços de comunicação e a evolução temporal. No que concerne à estrutura, reunem-se os elementos relativos à forma como está organizada a comunidade, a possível existência de níveis hierárquicos, o modo de gestão, o foco de publicação e iniciativas próprias.

Importa ainda analisar a dinâmica da comunidade, através do fluxo dos seus membros, frequência e forma de participação, o valor desta, relações ocorridas, a coesão, o modo de resolução de potenciais conflitos e a perceção geral do ambiente vivenciado. Para além destes traços, ajuizar da relevância da comunidade para os seus membros é um traço essencial, através da análise das expectativas iniciais, a mais valia acordada à participação na mesma, as razões para essa participação e o interesse na partilha. Por último, é decisivo para ajuizar da sua importância como comunidade virtual de prática, proceder à análise global da comunidade, para o que importa verificar a possível existência de constrangimentos por força da tecnologia, as perspetivas de desenvolvimento e os aspetos e fatores que potenciam ou o limitam, o impacto nos membros aderentes, os níveis de satisfação e os dados relativos ao domínio, ao estado de desenvolvimento, à diversidade de trajetórias e ao tipo de participação a elas associado.

\section{Conclusão}

As redes e comunidades virtuais de prática são parte integrante das novas formas de organização social que proliferam atualmente na Rede.

Estas granularidades constituem-se num campo de investigação aberto e relativamente recente, pelo que importa refletir sobre os instrumentos de recolha de dados e encontrar um modo de organização tão abrangente quanto possível para descrever toda a sua riqueza e especificidades. Foi esse o desafio a que nos propusemos aqui partilhar.

Como técnica predominante, a observação revelou-se vantajosa e eficaz. Na verdade, defendemos que para investigar comunidades ou outras formas de organização da Rede, em ambiente virtual, será imprescindível respeitar as rotinas e o natural pulsar e desenvolvimento de cada comunidade. Acresce ainda que, na senda destes pressupostos, defendemos uma observação não participante já que se afigura determinante a análise de cada comunidade sem que a nossa presença seja notada, não chamando a atenção para nós, observando o que é comum durante o tempo suficiente para compreender "o que, para este caso, significa ser comum" (Stake, 2007, p. 59).

Com efeito, os dados obtidos através desta técnica permitiram ultrapassar limitações derivadas da dificuldade de respostas aos questionários. Tendo também em conta a grande diversidade de dados, a triangulação destes, obtidos com instrumentos 
variados, em diferentes períodos temporais e provenientes dos diferentes atores (administradores e participantes), para além da análise dos diversos espaços, revelou-se como imprescindível. Para facilitar esta triangulação, a matriz elaborada constituiu-se como um instrumento eficaz e operativo.

Com efeito, tendo sido necessário recorrer a diferentes técnicas de recolha de dados, a matriz de análise criada permitiu retratar todas as características de cada comunidade estudada - desde os editais publicados até à interação dos seus membros nos diferentes fóruns e espaços de cada comunidade e ao mesmo tempo revelou-se adequada em termos de comparabilidade dos casos em contextos tão diversos.

No que concerne à diversidade de dados recolhidos não nos pareceu excessivo porquanto os mesmos vieram a acolher a opinião de membros e administradores permitindo uma complementaridade de opiniões e que veio enriquecer a nossa análise. Contudo, refletindo quanto às limitações da matriz de análise agora apresentada, apenas a salientar que a elevada quantidade de dados recolhidos originou um trabalho laborioso e moroso aquando da respetiva sistematização.

Em síntese, acreditamos que a metodologia adotada e a matriz apresentada são passíveis de adoções futuras pelo que estamos em crer ser um contributo para a análise das novas formas de organização social, existentes na rede.

\section{Referências Bibliográficas}

Anderson, T. \& Dron, J. (2007). Groups, Networks and Collectives in Social Software for E-learning. ECEL, 2007: $6^{\text {th }}$ European Conference on E-learning Copenhagen Business School (p. 15). Consultado em 19 de março de 2013. http://books.google.pt/ books?id=spo9X16qn30C\&pg=PA15\&dq=Groups ,+Networks+and+Collectives\%2Banderson\&hl=pt-PT\&sa=X\&ei=swZFUcHAFMfb7Aa9z4Al\#v=one page\&q\&f=false.

Bardin, L. (2004). Análise de Conteúdo. Lisboa: Edições 70.

Borgatti, S.P., Everett, M.G. and Freeman, L.C. (2002). UCINET for Windows. Software for Social Network Analysis. Harvard, MA: Analytic Technologies Versão 6.289.

Bratkovic, T.; Antoncic, B. \& Ruzzier, M. (2009). The Personal Network of the Owner-Manager of a Small Family Firm: The Crucial Role of the Spouse. In Managing Global Transitions. Consultado em 24 de dezembro de 2012. http://www.fm-kp.si/zalozba/ISSN/1581-6311/7_171-190.pdf.

Denzin, N.; Lincoln, Y. (Editores). Handbook of qualitative research. Thousand Oaks, California: Sage Publications, 1994.

Downes, S. (2006). Learning Networks and Connective Knowledge, http://www.ingedewaard.net/papers/ connectivism/2006_Downes_learningNetworks_and_ConnectiveKnowledge.pdf. Consultado em 11 de Janeiro de 2012.

Downes, S. (2007). Groups vs Networks: The Class Struggle Continues, 2007. Consultado em 06 de Janeiro de 2012. http://www.downes.ca/presentation/53. 
Flick, U. (2005). Métodos Qualitativos na Investigação Científica. Lisboa: Monitor.

Holsti, O.R. (1969). Content Analysis for Social Sciences and Humanities. Reading, Addison-Wesley.

Ghiglione, R.; Matalon, B. (2005). O inquérito. Teoria e Prática. Oeiras: Celta.

Lave, J. \& Wenger, E. (1991). Situated learning: Legitimate peripheral participation. Cambridge: Cambridge University Press.

Lemieux, V.; Ouimet, M. (2008). Análise Estrutural das Redes Sociais. Lisboa: Instituto Piaget.

Merriam, S. B. (1998). Qualitative Research and Case Study Applications in Education. San Francisco: Jossey-Bass.

Murillo, E. (2002). Using Social Network Analysis to detect cohesive subgroups in Usenet newsgroups: an initial approximation to the study of "virtual" Communities of Practice. Bradford: University of Bradford.

Neuman, W. (2006). Social Research Methods - qualitative and quantitative approaches (Sixth Edition). Boston: Pearson International Edition.

Patton, M. (1985). Quality in qualitative research: Methodological principles and recent developments. Chicago: Division J of the American Educational Research Association.

Siemens, G. (2004). Connectivism: A Learning Theory for the Digital Age. Elearnspace. Consultado em 27 de março de 2013. http://www.elearnspace.org/Articles/connectivism.htm.

Smith, M. K. $(2003$, 2009). Communities of practice. In The encyclopedia of informal education. Consultado em 27 de Outubro de 2011. http://infed.org/biblio/communities_of_practice.htm

Stake, R. Case Studies. In Denzin, N.; Lincoln, Y. (Editores) (1994). Handbook of qualitative research. Thousand Oaks, California: Sage Publications.

Stake, R. (2007). A Arte da Investigação com Estudos de Caso. Lisboa: Fundação Calouste Gulbenkian.

Wenger, E. (1998).Communities of practice: learning, meaning and identity. New York: Cambridge University Press.

Wenger, E.; McDermott, R. \& Snyder, W. M. (2002). Cultivating Communities of Practice: a guide to managing knowledge. Boston: Harvard Business School Press

Wenger, E. \& Trayner, B. (2011). How is a community of practice different from an informal network in regard to social learning?,.In Wenger-Trainer blog. (Mensagem de blog). Consultado em 19 de março de 2013. http://wenger-trayner.com/resources/communities-versus-networks/.

Wenger, E.; Trayner, B. \& de Laat, M. (2011). Promoting and assessing value creation in communities and networks: a conceptual framework. Ruud de Moor Centrum: Open Universiteit rdmc.ou.nl

Yin, R. (2009).Case Study Research - Design and Methods. Fourh Edition. Thousand Oaks, California: Sage Publications Inc. 
Antonieta Rocha

Laboratório de Educação a Distância e Elearning (LE@D), Universidade

Aberta

Email: mrocha@lead.uab.pt

Alda Pereira

Laboratório de Educação a Distância e Elearning (LE@D) Universidade

Aberta

Email: amp@uab.pt

Correspondência

Antonieta Rocha

Laboratório de Educação a Distância e Elearning (LE@D)

Universidade Aberta

Rua da Escola Politécnica

1269-001 Lisboa

Data de submissão: Julho 2016

Data de avaliação: Outubro 2016

Data de publicação: Julho 2017 